\title{
Ondřejov radar observations of Leonid shower activity in 2000-2002 ${ }^{\star}$
}

\author{
P. Pecina and D. Pecinová
}

\author{
Astronomical Institute of the Academy of Sciences of the Czech Republic, 25165 Ondřejov, Czech Republic \\ e-mail: ppecina@asu.cas.cz
}

Received 18 February 2004 / Accepted 8 July 2004

\begin{abstract}
Results of Ondřejov radar observations of the Leonid meteor shower in 2000, 2001 and 2002 are presented. Three years of observations covered the solar longitude interval of shower activity from $234^{\circ} .85$ to $237^{\circ} .25$ (J2000.0). The shower activity in 2000 and 2001 spread over two days while in 2002 over only a few hours during one day. The highest activity level was detected in 2002 and the lowest one in 2001. No activity of underdense radiometeors was registered in 2001. From all studied years the 2002 activity expressed in 30-min rates of overdense echoes was richest in comparison with corresponding rates in remaining years. The activity curves in 2000 and 2001 consisted of many peaks of widely fluctuating character while the corresponding curve in 2002 was formed by only one well pronounced maximum followed by one secondary one. One of the smaller peaks in 2000 at $L_{\odot}=236^{\circ} 11$ (4h15m UT on Nov. 18) appeared also in 2001 at the same solar longitude (10h15m UT on Nov. 18) as the strongest maximum in this year. Comparison of the mass distribution indices, $s$, computed from overdense echo rates (registered within main activity peaks) showed that they were lowest in 2000 when they approached $s \simeq 1.13$ while they were highest in 2002 when $s \simeq 1.22$ indicating that the proportion of fainter meteors in the observed data sample increased from 2000 to 2002. We have compared the activity with predictions from the literature. We have confirmed a few peaks predicted although they were not always produced by meteors of all four echo categories we defined. This corresponds to different activity of meteoroids of different masses. Moreover, we have also found remarkable activity on Nov. 19, 2001 which was not predicted.
\end{abstract}

Key words. comets: individual: 55P/Tempel-Tuttle - meteors, meteoroids

\section{Introduction}

The return of the parent comet of the Leonid meteor stream, 55P/Tempel-Tuttle, to the vicinity of the Sun in 1998 generated an increased interest in the study of the shower display associated with it. A lot of studies were carried out using a variety of techniques including radar. This paper updates the observations performed in 1998 and 1999 with the Ondřejov meteor radar, which was described by Šimek \& Pecina (2001) and completes their previous studies (e.g. Šimek \& Pecina 2000). We present shower activity curves for both underdense and overdense echoes as well as the mass distribution index $s$ behaviour. To relate our observations to theories of formation of various filaments of the Leonid meteor stream we compare our results with predictions put forward by Asher \& McNaught (2000), Jenniskens (2001), Lyytinen et al. (2001), McNaught \& Asher $(2001,2002)$ and Vaubaillon (2002). We pay more detailed attention to the appearance of echoes of various duration characteristics (i.e. meteors of various masses) in order to enable further study of the filamentary structure of the Leonid stream.

* Tables 5-7 are only available in electronic form at http://www. edpsciences.org
We hope that our findings can be useful for further studies of filamentary structure of Leonids and of the ejection process itself.

\section{Equipment and observations}

The observations of the Leonid shower in all three years were carried out with the Ondrejov meteor radar located at $\left(49^{\circ} 54^{\prime} 38^{\prime \prime} \mathrm{N}, 14^{\circ} 47^{\prime} 01^{\prime \prime} \mathrm{E}\right)$, which has been operating since 1958 (e.g. Plavcová \& Šimek 1960). It transmits at a frequency of $37.5 \mathrm{MHz}$ with a pulse length of $10 \mu \mathrm{s}$, a peak power of $10 \mathrm{~kW}$, and a repetition frequency of $500 \mathrm{~Hz}$. The beam-width of the antenna system is approximately $52^{\circ}$ in the vertical plane and $36^{\circ}$ in the plane orthogonal to the former which is fixed at $50^{\circ}$ elevation. The elevation of the main lobe maximum is $50^{\circ}$ while the elevation of the secondary lobe one is about $17^{\circ}$ above the horizon. The antenna is steerable only in azimuth. During the whole three years, whose observations are reported here, the antenna followed the intersection of the highest possible direction from the set of following almucan$\operatorname{tars} 50^{\circ}, 48^{\circ}, 46^{\circ}, 44^{\circ}, 42^{\circ}$, and $17^{\circ}$ with the $90^{\circ}$ circle centered at the shower radiant whenever possible. This was chosen to 
Table 1. Observing periods in years 2000-2002. Time periods of each year are labeled with the beginning day in Nov., bd, the end day, ed, the beginning hour and minute, bh and bm, and end hour and minute, eh and em, respectively of each particular period, in UT, and with the corresponding solar longitudes, $b L_{\odot}$ and $e L_{\odot}$ [J2000.0]. The last column indicates whether the period was considered a background (i.e. b) or shower (i.e. s) activity. These periods were the same for all 4 categories of echoes except for 2000 when also the interval from $L_{\odot}=234.85$ to $L_{\odot}=235^{\circ} .46$ was used as a background for echoes having $T \geq 10.0 \mathrm{~s}$.

\begin{tabular}{|c|c|c|c|c|c|c|c|c|}
\hline \multicolumn{9}{|c|}{2000} \\
\hline \multicolumn{4}{|c|}{ Beginning } & \multicolumn{4}{|c|}{ End } & \multirow[b]{2}{*}{$\mathrm{b} / \mathrm{s}$} \\
\hline $\mathrm{bd}$ & bh & $\mathrm{bm}$ & $\overline{b L_{\odot}}$ & ed & eh & em & $e L_{\odot}$ & \\
\hline 14 & 22 & 00 & $232^{\circ} .84$ & 15 & 13 & 00 & $233^{\circ} .47$ & $\mathrm{~b}$ \\
\hline 16 & 4 & 40 & $234^{\circ} .13$ & 16 & 10 & 52 & 234.39 & $\mathrm{~b}$ \\
\hline 16 & 22 & 00 & $234^{\circ} .85$ & 17 & 12 & 23 & $235^{\circ} .46$ & $\mathrm{~s}$ \\
\hline 17 & 22 & 00 & $235^{\circ} .86$ & 18 & 13 & 00 & $236^{\circ} .49$ & s \\
\hline 18 & 22 & 00 & $236: 87$ & 19 & 13 & 00 & 237.50 & $\mathrm{~b}$ \\
\hline \multicolumn{9}{|c|}{2001} \\
\hline & \multicolumn{3}{|c|}{ Beginning } & \multicolumn{4}{|c|}{ End } & \\
\hline bd & bh & $\mathrm{bm}$ & $b L_{\odot}$ & ed & eh & $\mathrm{em}$ & $e L_{\odot}$ & $\mathrm{b} / \mathrm{s}$ \\
\hline 15 & 22 & 00 & $233^{\circ} .59$ & 16 & 13 & 00 & $234^{\circ} .22$ & $\mathrm{~b}$ \\
\hline 16 & 22 & 00 & 234.60 & 17 & 13 & 00 & $235^{\circ} .23$ & $\mathrm{~b}$ \\
\hline 17 & 22 & 00 & $235^{\circ} .61$ & 18 & 13 & 00 & $236^{\circ} .24$ & $\mathrm{~s}$ \\
\hline 18 & 22 & 00 & $236^{\circ} 62$ & 19 & 13 & 00 & $237^{\circ} .25$ & $\mathrm{~s}$ \\
\hline \multicolumn{9}{|c|}{$\overline{\overline{2002}}$} \\
\hline & \multicolumn{3}{|c|}{ Beginning } & \multicolumn{4}{|c|}{ End } & \\
\hline $\mathrm{bd}$ & bh & bm & $b L_{\odot}$ & ed & eh & em & $e L_{\odot}$ & $\mathrm{b} / \mathrm{s}$ \\
\hline 14 & 23 & 00 & $232^{\circ} .37$ & 15 & 13 & 00 & 232.96 & $\mathrm{~b}$ \\
\hline 17 & 23 & 00 & $235^{\circ} .39$ & 18 & 13 & 00 & $235^{\circ} .98$ & $\mathrm{~b}$ \\
\hline 18 & 23 & 00 & $236^{\circ} .40$ & 19 & 13 & 00 & 236.99 & $\mathrm{~s}$ \\
\hline 19 & 23 & 00 & $237^{\circ} .41$ & 20 & 13 & 00 & $238^{\circ} .00$ & $\mathrm{~b}$ \\
\hline
\end{tabular}

observe within the direction of highest possible antenna sensitivity for the longest possible period. The period of observation is limited to the interval in which the shower radiant is above the horizon. Since it is impossible to register Leonid meteors by means of our antenna system when the radiant is close to the local horizon we have selected the period of observation from one hour after its rise to one hour before its set. A summary of our executing times is given in Table 1. The methodology and observing conditions together with disturbing noise were of the same level within all three years.

\section{Activity profiles}

To obtain shower activity curves in each of these years, the background activity rates were determined from observed counts in particular time intervals in background periods as they are listed in Table 1. The background periods were established as those with low observed rates corresponding to long-term observations of the Leonid stream and not according to the predictions about the appearance of the main storms. The observed rates were first corrected for interruptions. 30-min intervals proved to be the most suitable to demonstrate the shower activity regarding statistical processing of recorded rates of echoes. All echoes were divided into 4 categories. These are underdense echoes whose duration does not

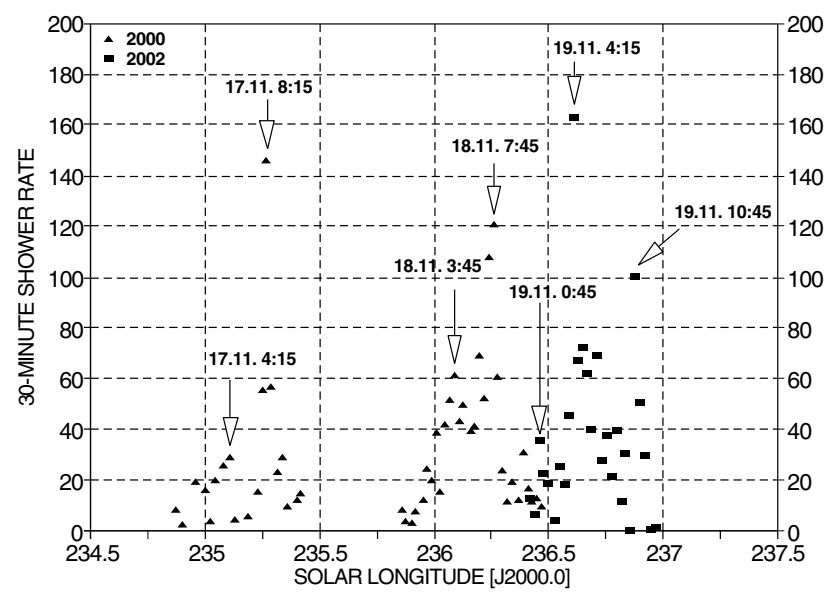

Fig. 1. Comparison of activity of underdense echoes recorded within 2000-2002. The year 2001 did not display any activity of underdense echoes at all. The important time instants of maximum activity are marked by arrows accompanied by the day in November and time instant in UT.

exceed $0.4 \mathrm{~s}$, and 3 groups of overdense echoes having duration greater or equal than $0.4 \mathrm{~s}, 1.0 \mathrm{~s}$, and $10.0 \mathrm{~s}$, respectively. For example, meteors of the 3rd group have durations in the interval $[1.0,+\infty)$ s. Statistically determined background rates were subtracted from corresponding rates observed during the shower period yielding the net shower rates. Since we could neglect the daily motion of the radiant due to the wide antenna beam and short time interval of observations (a few days), a particular time interval within the shower period was considered as the same within the background period, both being influenced by daily variation of radiant position and method of observation in the same way. We have not recomputed our shower rates to ZHRs since such a recomputation is irrelevant for radar observations. It is a consequence of the fact that a radar collecting area is not simply a function of $\cos z_{R}$ as assumed for visual observations. Moreover, it depends also for example on the mass distribution index, $s$ (e.g. Jenniskens 1994; Belkovich et al. 2001). The positions of activity peaks are not influenced by our procedure. Results valid for a particular duration and for all 3 years are depicted in Figs. 1-4, for a comparison of activity levels of the examined years within these categories. We also show curves of individual overdense duration in each year in Figs. 5-7 for better comparison. The points of maxima are the instants of interval centres; instants of maxima are determined with an error of $15 \mathrm{~min}$. The positions of all major activity peaks are listed in Tables $2-4$. The results of each analysed year are discussed later in the corresponding subsections.

In order to connect the peaks of activity curves of overdense echoes with the mass distribution, the $s$-index curves are included in Figs. 8-10. The relation of these activities to meteors of various masses will be discussed in the section devoted to mass distribution of the shower. 


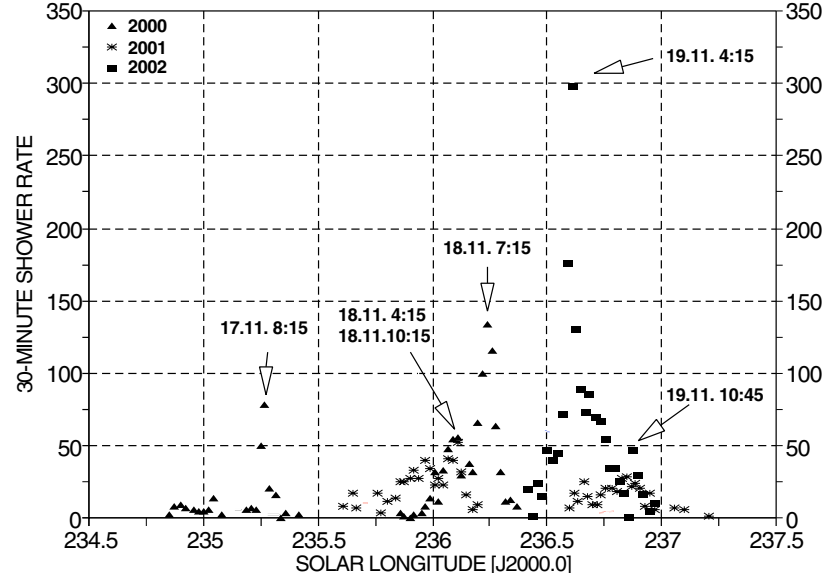

Fig. 2. Comparison of activity of overdense echoes with $T \geq 0.4 \mathrm{~s}$ recorded within 2000-2002. The important time instants of maximum activity are marked by arrows accompanied by the day in November and time instant in UT.

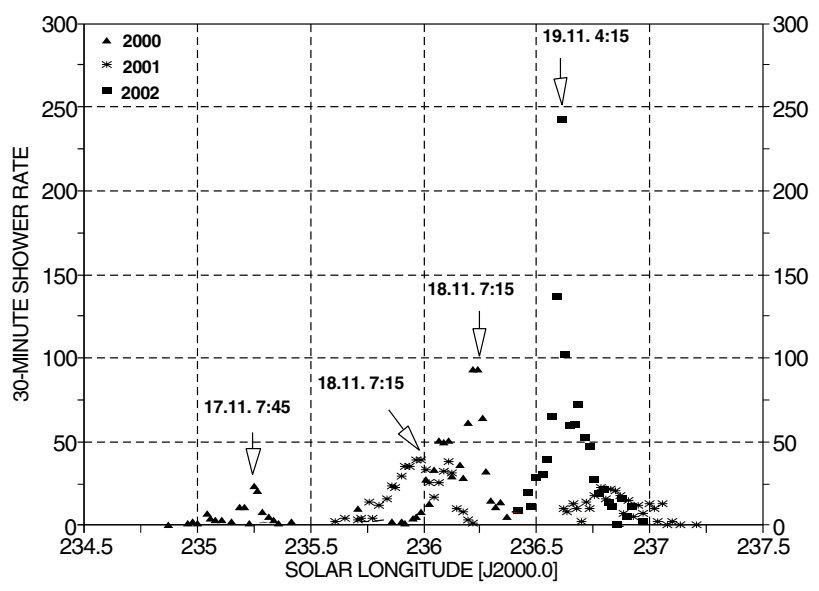

Fig. 3. The same as in Fig. 2 but for echoes with $T \geq 1.0 \mathrm{~s}$.

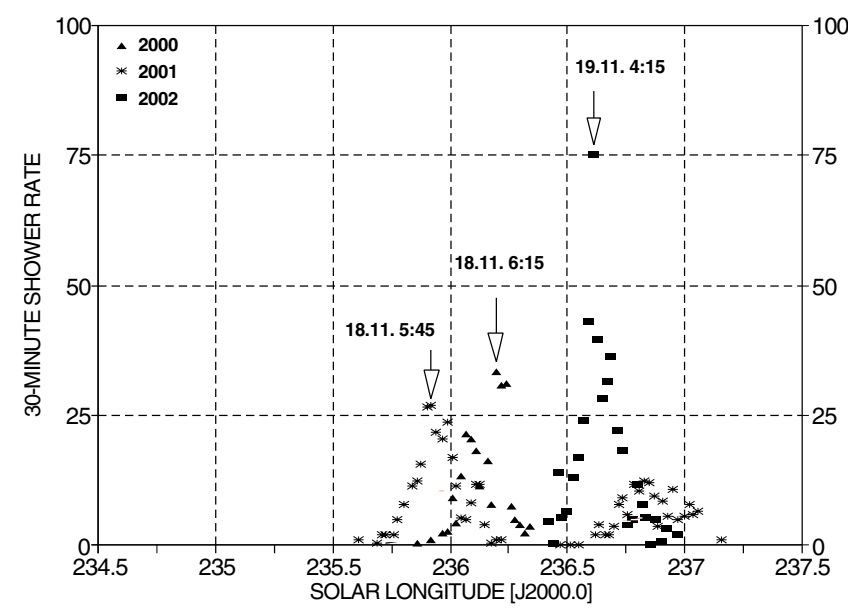

Fig. 4. The same as in Fig. 2 but for echoes with $T \geq 10.0 \mathrm{~s}$.

\subsection{0}

As shown in Figs. 1-5, the 2000 activity lasted two days, 17th and 18th of November, except for the group with $T \geq 10.0 \mathrm{~s}$, which was active only on Nov. 18. The solar longitudes of all major activity peaks are listed in Table 2 together with their

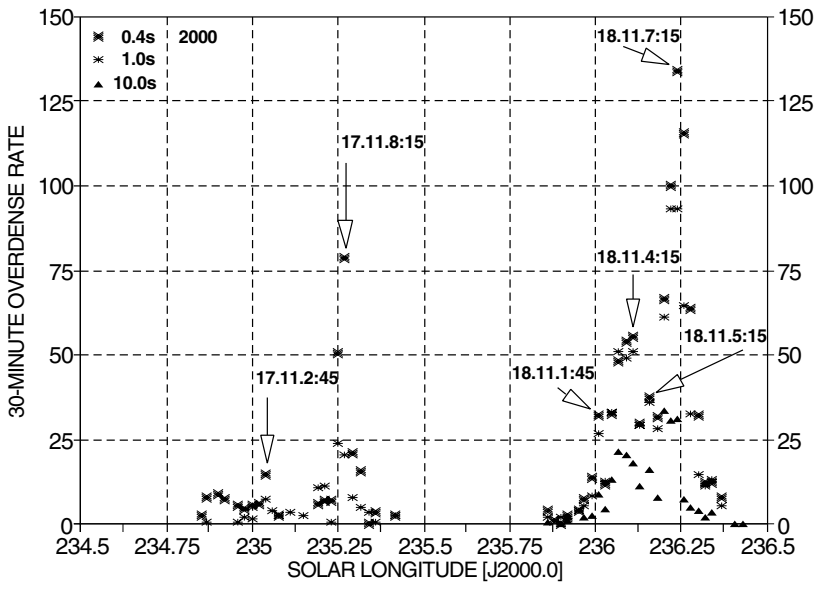

Fig. 5. The 30-min shower overdense rate of the three groups in 2000 . Crosses represent the group of $T \geq 0.4 \mathrm{~s}$, asterisks mark the second one of $T \geq 1.0 \mathrm{~s}$, full triangles indicate $T \geq 10.0 \mathrm{~s}$. The important and interesting peaks are listed in Table 2 .

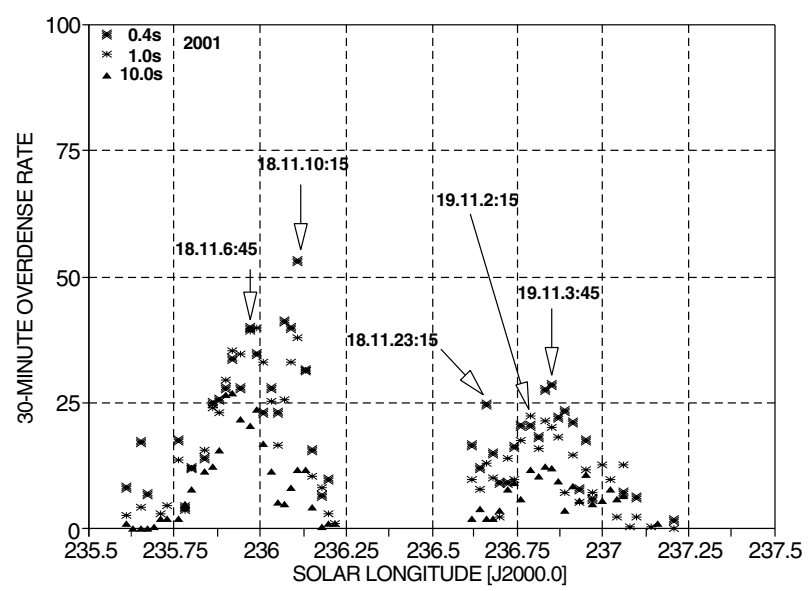

Fig. 6. The same as in Fig. 5 but for 2001. The important and interesting peaks are listed in Table 3.

rates and time instants. We list separate data points within the broader peaks so that the reader would have the individual data points available. The same concerns also the subsequent two tables for the other two years.

Examination of the Leonid's underdense activity curve in 2000 revealed two main peaks (Fig. 1). The former and stronger maximum occurred at $8 \mathrm{~h} 15 \mathrm{~m}$ UT on Nov. 17 (corresponding to $L_{\odot}=235^{\circ} 27$ ) and it is the strongest of all maxima in 2000 . The latter and slightly weaker one appeared at $7 \mathrm{~h} 45 \mathrm{~m}$ UT on Nov. $18\left(L_{\odot}=236.26\right)$. In addition, a closer study brought to light a few smaller interesting maxima, as seen in Fig. 1 and Table 2.

The activity profile in the group with $T \geq 0.4 \mathrm{~s}$ is characterized by several places of enhanced activity. In general, we can say that whereas there was the main maximum on Nov. 17 in the group of underdense echoes, Nov. 18 was richer with the occurrence of all overdense echoes in comparison with the previous day. As shown in Figs. 2, 5 and in Table 1, the first important peak was found on Nov. 17 at $8 \mathrm{~h} 15 \mathrm{~m} \mathrm{UT}\left(L_{\odot}=235^{\circ} 27\right)$. The comparison of activity within all defined groups enables us to arrive at the conclusion that the activity on Nov. 17, 


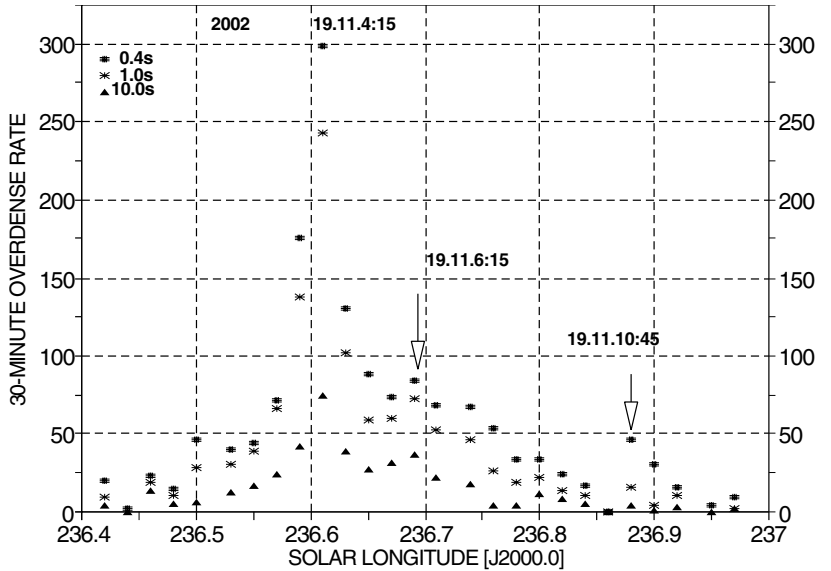

Fig. 7. The same as in Fig. 5 but for 2002. The important and interesting peaks are listed in Table 4 . The data between $10 \mathrm{~h} 00 \mathrm{~m}$ and $10 \mathrm{~h} 30 \mathrm{~m}$ had to be excluded from data processing because of the very bad quality of the film within this interval.

Table 2. Positions of main activity peaks recorded in 2000. The instants of the maxima are determined with an error of $15 \mathrm{~min}$. Our observations corresponding to the forecast of Asher \& McNaught (2000) are presented in bold (see Sect. 5.1).

\begin{tabular}{|c|c|c|c|c|c|}
\hline \multirow[t]{2}{*}{ duration } & \multicolumn{3}{|c|}{ time [UT] } & \multirow{2}{*}{$\begin{array}{c}L_{\odot} \\
\mathrm{J} 2000.0 \\
\end{array}$} & \multirow{2}{*}{$\begin{array}{c}\text { 30-min } \\
\text { shower rate }\end{array}$} \\
\hline & day & hour & $\min$ & & \\
\hline \multirow[t]{5}{*}{$T<0.4 \mathrm{~s}$} & 17 & 4 & 15 & $235: 11$ & 29.16 \\
\hline & 17 & 8 & 15 & $235: 27$ & 146.13 \\
\hline & 18 & 3 & 45 & 236.09 & 61.67 \\
\hline & 18 & 7 & 45 & 236.26 & 120.69 \\
\hline & 18 & 10 & 45 & 236.39 & 30.98 \\
\hline \multirow[t]{7}{*}{$T \geq 0.4 \mathrm{~s}$} & 17 & 2 & 45 & $235^{\circ} .04$ & 14.46 \\
\hline & 17 & 8 & 15 & $235^{\circ} .27$ & 78.50 \\
\hline & 18 & 1 & 45 & 236.01 & 31.94 \\
\hline & 18 & 4 & 15 & $236: 11$ & 55.65 \\
\hline & 18 & 5 & 15 & $236: 16$ & 37.36 \\
\hline & 18 & 7 & 15 & $236: 24$ & 133.58 \\
\hline & 18 & 7 & 45 & 236.26 & 115.51 \\
\hline \multirow{9}{*}{$T \geq 1.0 \mathrm{~s}$} & 17 & 6 & 45 & $235^{\circ} .21$ & 11.33 \\
\hline & 17 & 7 & 45 & $235^{\circ} .25$ & 23.78 \\
\hline & 18 & 1 & 45 & 236.01 & 26.66 \\
\hline & 18 & 3 & 15 & 236.07 & 51.12 \\
\hline & 18 & 3 & 45 & $236^{\circ} .09$ & 49.19 \\
\hline & 18 & 4 & 15 & $236: 11$ & 50.85 \\
\hline & 18 & 5 & 15 & $236: 16$ & 36.23 \\
\hline & 18 & 6 & 45 & 236.22 & 92.81 \\
\hline & 18 & 7 & 15 & 236.24 & 92.98 \\
\hline \multirow[t]{6}{*}{$T \geq 10.0 \mathrm{~s}$} & 18 & 1 & 45 & $236^{\circ} .01$ & 9.02 \\
\hline & 18 & 3 & 15 & 236.07 & 21.55 \\
\hline & 18 & 5 & 15 & $236: 16$ & 16.31 \\
\hline & 18 & 6 & 15 & 236.20 & 33.38 \\
\hline & 18 & 6 & 45 & 236.22 & 30.68 \\
\hline & 18 & 7 & 15 & $236^{\circ} .24$ & 31.13 \\
\hline
\end{tabular}

especially at this solar longitude, was predominantly caused by underdense echoes and overdense echoes with masses corresponding to durations in the span of $0.4 \mathrm{~s} \leq T<1.0 \mathrm{~s}$ (while echoes with $T \geq 10.0 \mathrm{~s}$ were not registered at all this day). The strongest peak appeared at $7 \mathrm{~h} 15 \mathrm{~m} \mathrm{UT}\left(L_{\odot}=236^{\circ} .24\right)$
Table 3. Positions of main activity peaks recorded in 2001. The instants of the maxima are determined with an error of $15 \mathrm{~min}$. Our observations corresponding to the forecast of Jenniskens (2001) and Lyytinen et al. (2001) are presented in bold (see Sect. 5.2).

\begin{tabular}{|c|c|c|c|c|c|}
\hline \multirow[t]{2}{*}{ duration } & \multicolumn{3}{|c|}{ time [UT] } & \multirow{2}{*}{$\begin{array}{c}L_{\odot} \\
\mathrm{J} 2000.0\end{array}$} & \multirow{2}{*}{$\begin{array}{c}30-m i n \\
\text { shower rate }\end{array}$} \\
\hline & day & hour & $\min$ & & \\
\hline \multirow[t]{4}{*}{$T \geq 0.4 \mathrm{~s}$} & 18 & 6 & 45 & $235^{\circ} .97$ & 39.66 \\
\hline & 18 & 10 & 15 & 236.11 & 52.99 \\
\hline & 18 & 23 & 15 & 236.66 & 24.50 \\
\hline & 19 & 3 & 45 & 236.85 & 28.24 \\
\hline \multirow[t]{5}{*}{$T \geq 1.0 \mathrm{~s}$} & 18 & 6 & 45 & $235^{\circ} .97$ & 39.15 \\
\hline & 18 & 7 & 15 & $235^{\circ} .99$ & 39.65 \\
\hline & 18 & 10 & 15 & $236: 11$ & 37.75 \\
\hline & 18 & 23 & 15 & $236: 66$ & 13.00 \\
\hline & 19 & 2 & 15 & 236.79 & 22.41 \\
\hline \multirow[t]{7}{*}{$T \geq 10.0 \mathrm{~s}$} & 18 & 5 & 15 & $235^{\circ} \cdot 90$ & 26.50 \\
\hline & 18 & 5 & 45 & $235: 92$ & 26.96 \\
\hline & 18 & 7 & 15 & $235^{\circ} .99$ & 23.61 \\
\hline & 18 & 10 & 15 & 236.11 & 11.76 \\
\hline & 18 & 10 & 45 & $236: 13$ & 11.56 \\
\hline & 19 & 3 & 15 & $236: 83$ & 12.51 \\
\hline & 19 & 3 & 45 & 236.85 & 12.00 \\
\hline
\end{tabular}

Table 4. Positions of main activity peaks recorded in 2002. The instants of the maxima are determined with an error of $15 \mathrm{~min}$. Our observations corresponding to the forecast of Jenniskens (2001), McNaught \& Asher (2002) and Vaubaillon (2002) are presented in bold (see Sect. 5.3).

\begin{tabular}{|c|c|c|c|c|c|}
\hline \multirow[t]{2}{*}{ duration } & \multicolumn{3}{|c|}{ time [UT] } & \multirow{2}{*}{$\begin{array}{c}L_{\odot} \\
\mathrm{J} 2000.0\end{array}$} & \multirow{2}{*}{$\begin{array}{c}30 \text {-min } \\
\text { shower rate }\end{array}$} \\
\hline & day & hour & $\min$ & & \\
\hline \multirow[t]{4}{*}{$T<0.4 \mathrm{~s}$} & 19 & 0 & 45 & $236: 46$ & 35.48 \\
\hline & 19 & 4 & 15 & $236: 61$ & 162.75 \\
\hline & 19 & 6 & 45 & 236.71 & 69.58 \\
\hline & 19 & 10 & 45 & $236^{\circ} 88$ & 100.66 \\
\hline \multirow[t]{5}{*}{$T \geq 0.4 \mathrm{~s}$} & 19 & 3 & 45 & $236^{\circ} .59$ & 175.63 \\
\hline & 19 & 4 & 15 & 236.61 & 297.98 \\
\hline & 19 & 4 & 45 & 236.63 & 130.50 \\
\hline & 19 & 6 & 15 & 236.69 & 84.88 \\
\hline & 19 & 10 & 45 & 236.88 & 46.39 \\
\hline \multirow[t]{5}{*}{$T \geq 1.0 \mathrm{~s}$} & 19 & 3 & 45 & 236.59 & 137.25 \\
\hline & 19 & 4 & 15 & $236^{\circ} .61$ & 243.02 \\
\hline & 19 & 4 & 45 & 236.63 & 101.53 \\
\hline & 19 & 6 & 15 & 236.69 & 72.08 \\
\hline & 19 & 10 & 45 & $236: 88$ & 16.07 \\
\hline \multirow[t]{2}{*}{$T \geq 10.0 \mathrm{~s}$} & 19 & 4 & 15 & $236^{\circ} .61$ & 75.02 \\
\hline & 19 & 6 & 15 & $236: 69$ & 36.35 \\
\hline
\end{tabular}

on Nov. 18, i.e. about 30 min earlier than the activity of underdense echoes reached its maximum. It was preceded by a smaller one at $4 \mathrm{~h} 15 \mathrm{~m}$ UT $\left(L_{\odot}=236.11\right)$, which was mainly caused by the presence of echoes with duration $T \geq 1.0 \mathrm{~s}$. There was a minor augmentation between them at $5 \mathrm{~h} 15 \mathrm{~m}$ UT that is preserved in each of group of overdense echoes. Another compelling growth in the Leonid activity became visible at $1 \mathrm{~h} 45 \mathrm{~m} \mathrm{UT}\left(L_{\odot}=236.01\right)$ and it could also be discerned in each group of overdense echoes.

The group with $T \geq 1.0 \mathrm{~s}$ has a slightly different character. The maximum of the previous group at $235^{\circ} 27$ is now shifted 


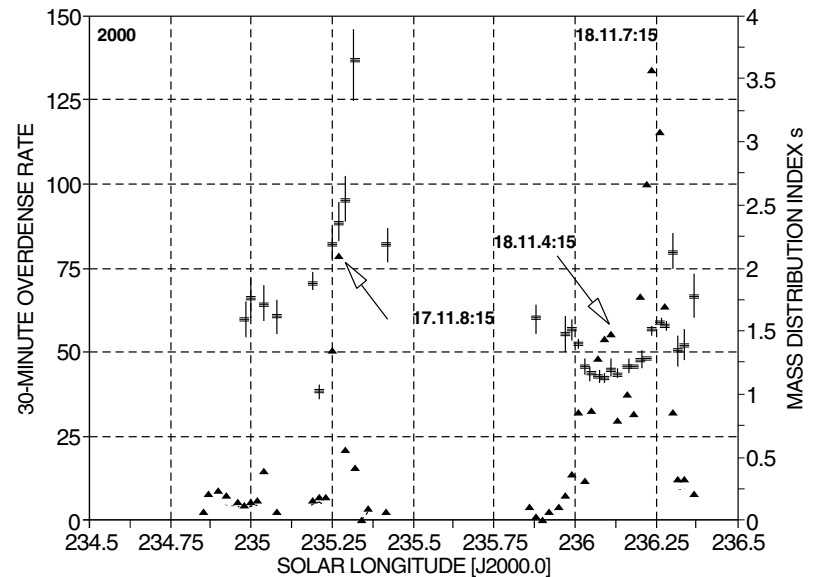

Fig. 8. The 30-min shower overdense echoes rate of echoes with $T \geq 0.4 \mathrm{~s}$ (full triangles) together with the course of mass distribution index, $s$, (full rectangle with vertical lines standing for error bars), in 2000. The important time instants of maximum activity are marked by arrows accompanied by the day in November and time instant in UT.

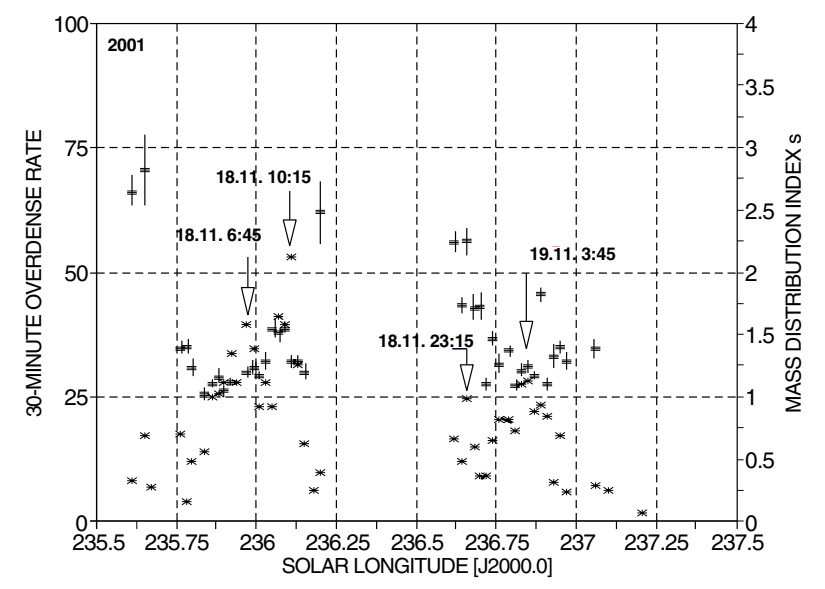

Fig. 9. The same as in Fig. 8 but for 2001 (asterisks).

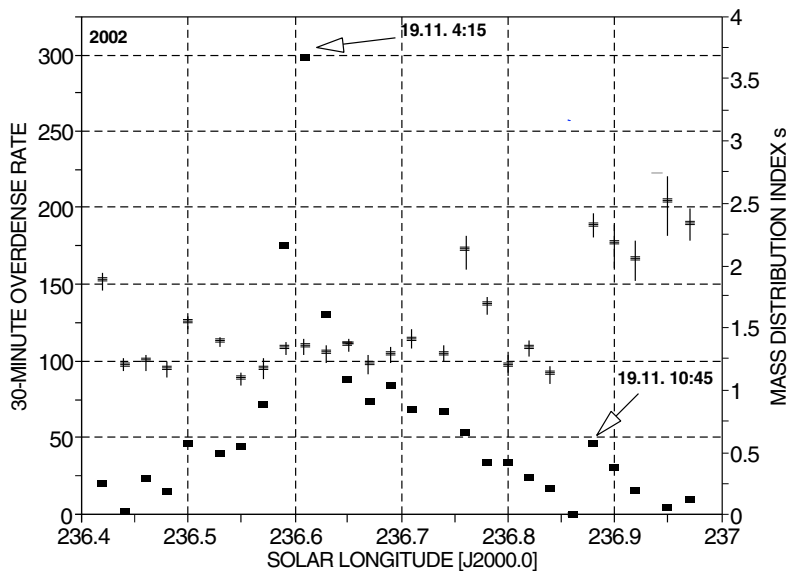

Fig. 10. The same as in Fig. 8 but for 2002 (full rectangles).

about 30 min back in time and becomes almost negligible in the whole activity of this group on Nov. 17 . Both of the most intensive peaks on Nov. 18 from the preceeding group are broadened to wider time intervals.
Table 8. Mass of a meteoroid as a function of time and duration, $T$. Meteoroid mass is in $10^{-6} \mathrm{~kg}$.

\begin{tabular}{rrrr}
\hline \hline time [UT] & $m_{\infty}(T=0.4 \mathrm{~s})$ & $m_{\infty}(T=1.0 \mathrm{~s})$ & $m_{\infty}(T=10.0 \mathrm{~s})$ \\
\hline $23 \mathrm{~h} 15 \mathrm{~m}$ & 14.9 & 40.2 & 491 \\
$23 \mathrm{~h} 45 \mathrm{~m}$ & 11.8 & 31.8 & 389 \\
$0 \mathrm{~h} 15 \mathrm{~m}$ & 9.0 & 24.3 & 297 \\
$0 \mathrm{~h} 45 \mathrm{~m}$ & 7.8 & 21.1 & 257 \\
$1 \mathrm{~h} 15 \mathrm{~m}$ & 6.7 & 18.1 & 222 \\
$1 \mathrm{~h} 45 \mathrm{~m}$ & 5.9 & 16.0 & 196 \\
$2 \mathrm{~h} 15 \mathrm{~m}$ & 5.4 & 14.7 & 180 \\
$2 \mathrm{~h} 45 \mathrm{~m}$ & 5.0 & 13.5 & 164 \\
$3 \mathrm{~h} 15 \mathrm{~m}$ & 4.7 & 12.7 & 155 \\
$3 \mathrm{~h} 45 \mathrm{~m}$ & 4.4 & 12.0 & 147 \\
$4 \mathrm{~h} 15 \mathrm{~m}$ & 4.3 & 11.7 & 143 \\
$4 \mathrm{~h} 45 \mathrm{~m}$ & 4.2 & 11.5 & 140 \\
$5 \mathrm{~h} 15 \mathrm{~m}$ & 4.2 & 11.4 & 139 \\
$5 \mathrm{~h} 45 \mathrm{~m}$ & 4.2 & 11.4 & 139 \\
$6 \mathrm{~h} 15 \mathrm{~m}$ & 4.3 & 11.6 & 142 \\
$6 \mathrm{~h} 45 \mathrm{~m}$ & 4.4 & 12.0 & 147 \\
$7 \mathrm{~h} 15 \mathrm{~m}$ & 4.6 & 12.5 & 152 \\
$7 \mathrm{~h} 45 \mathrm{~m}$ & 4.9 & 13.2 & 162 \\
$8 \mathrm{~h} 15 \mathrm{~m}$ & 5.2 & 14.2 & 173 \\
$8 \mathrm{~h} 45 \mathrm{~m}$ & 5.8 & 15.7 & 191 \\
$9 \mathrm{~h} 15 \mathrm{~m}$ & 6.5 & 17.7 & 216 \\
$9 \mathrm{~h} 45 \mathrm{~m}$ & 7.5 & 20.4 & 249 \\
$10 \mathrm{~h} 15 \mathrm{~m}$ & 9.0 & 24.3 & 297 \\
$10 \mathrm{~h} 45 \mathrm{~m}$ & 10.6 & 28.8 & 352 \\
$11 \mathrm{~h} 15 \mathrm{~m}$ & 13.9 & 37.7 & 461 \\
$11 \mathrm{~h} 45 \mathrm{~m}$ & 18.5 & 50.2 & 613 \\
\hline & & &
\end{tabular}

The overdense echoes with $T \geq 10.0 \mathrm{~s}$ (the brightest meteors) did not appear on Nov. 17 at all, as we have already mentioned above. Both main maxima on Nov. 18 occurred as well, but they were even more widespread and less numerous in comparison to the preceding duration group.

\subsection{1}

The activity in 2001 can be seen from Figs. 2-4 and 6. The solar longitudes of all major activity peaks are listed in Table 3.

2001 was the poorest year of all three examined from the point of view of recorded shower rates. The activity in the group of underdense echoes was imperceptible, which is, as we consider, one of the most interesting and valuable findings of our study. It could not be explained by any outer interference since the methodology and observing conditions were the same and the noise was comparable within all three years. It is thus a property of the shower activity itself and it means that no meteors were recorded with masses less than the ones according to duration $T=0.4 \mathrm{~s}$ (see Table 8 ).

As discussed above, the Leonid event in 2001 was entirely due to overdense echoes, i.e. brighter meteors. The activity in all three overdense groups manifested over two days, as did the 2000 activity. In general, Nov. 18 showed more overdense echoes than Nov. 19.

On Nov. 18 the group with $T \geq 0.4 \mathrm{~s}$ had the strongest peak at $10 \mathrm{~h} 15 \mathrm{~m}$ UT $\left(L_{\odot}=236^{\circ} 11\right)$. A less intensive peak appeared before that at $6 \mathrm{~h} 45 \mathrm{~m} \mathrm{UT}\left(L_{\odot}=235^{\circ} 97\right)$. Another smaller maximum occurred at $23 \mathrm{~h} 15 \mathrm{~m} \mathrm{UT}\left(L_{\odot}=236.66\right)$ within the 
consecutive period of observation. On Nov. 19 at $3 \mathrm{~h} 45 \mathrm{~m}$ UT another maximum followed $\left(L_{\odot}=236^{\circ} 85\right)$, which is only a bit stronger than that at $23 \mathrm{~h} 15 \mathrm{~m}$ UT on Nov. 18 .

The activity curve of echoes having $T \geq 1.0 \mathrm{~s}$ has a similar course as in the previous group on Nov. 18 but there are several differences. The radar recorded two main peaks instead of one. The maximum at $235^{\circ} .97$ lasted for a longer time interval (about one hour, from $6 \mathrm{~h} 30 \mathrm{~m}$ to $7 \mathrm{~h} 30 \mathrm{UT}$ ) and had the same level of echo rate as the previous group. It indicates that this peak is exclusively from echoes having $T \geq 1.0 \mathrm{~s}$. Meteors with $0.4 \mathrm{~s} \leq T<1.0 \mathrm{~s}$ appeared later at $236^{\circ} .11$. The maximum at $23 \mathrm{~h} 15 \mathrm{~m}$ UT on Nov. 19 is not so pronounced but it is still preserved on the activity curve. The peak of previous group at $3 \mathrm{~h} 45 \mathrm{~m}$ UT on this day was shifted back to $236^{\circ} .79$ and split into two.

The maximum of echoes with $T \geq 10.0 \mathrm{~s}$ on Nov. 18 split into two peaks, of which the first one became apparent earlier, at $5 \mathrm{~h} 45 \mathrm{~m}$ UT $\left(L_{\odot}=235^{\circ} .92\right)$. The peak at $10 \mathrm{~h} 15 \mathrm{~m}$ UT converted into a small one, not very striking. On Nov. 19 there was a small peak at the same time as in the first category of overdense echoes ( $3 \mathrm{~h} 15 \mathrm{~m} \mathrm{UT}$ ). But the maximum at $23 \mathrm{~h} 15 \mathrm{~m} \mathrm{UT}$ on Nov. 19 was almost not recognizable. On Nov. 18 the maxima were gradually shifted backward when our interest was focused on echoes with greater duration. Hence, the brightest meteors began to appear first and then gradually the fainter ones started to be active. But on the other hand the length of active time of echoes from the last group was the shortest.

\subsection{2}

The activity in 2002 is demonstrated in Figs. 1-4 and 7. The solar longitudes of all major activity peaks are listed in Table 4. The Leonid shower in 2002 in all duration categories was active during only one day, i.e. on Nov. 19. In spite of this fact, 2002 was the richest in number of recorded Leonid echoes from all three years.

The main peak was recorded at $4 \mathrm{~h} 15 \mathrm{~m} \mathrm{UT}\left(L_{\odot}=236.61\right)$ and it remained in each of the four examined duration groups. Activity profiles in all categories have almost the same course. There was a fairly fast increase in rates before reaching the main peak and after that there was a gradual descent with a small sudden increase at $6 \mathrm{~h} 15 \mathrm{~m}$ UT $\left(L_{\odot}=236.69\right)$. This smaller maximum is visible in each of three overdense activity curves while the faintest meteors registered with the meteor $\operatorname{radar}(T<0.4 \mathrm{~s})$ had this increase about 30 minutes later, at $6 \mathrm{~h} 45 \mathrm{~m}$ UT. There is one another interesting peak at $10 \mathrm{~h} 45 \mathrm{~m} \mathrm{UT}\left(L_{\odot}=236.88\right)$, in which the radar detected mainly echoes with durations inside the interval $0.4 \mathrm{~s} \leq T<10.0 \mathrm{~s}$ and underdense echoes.

\section{Mass distribution}

Information about the proportional representation of meteoroids of different masses can be inferred from the mass distribution represented by the well-known mass distribution index, $s$. These were computed from the slope of a linear part of the curve $\log _{10} N_{\mathrm{c}}$ vs. $\log _{10} T$ where $\log _{10} N_{\mathrm{c}}$ is the logarithm of the cumulative number of observed shower echoes and $\log _{10} T$ is the logarithm of observed echo duration of overdense echoes. The index $s$ was calculated from cumulative counts, of the shower echoes, $N_{\mathrm{c}}$, in 14 echo duration classes, $T$, within the interval of 0.4-7.5 s according to the formula (Kaiser 1955)

$\log _{10} N_{\mathrm{c}}=-\frac{3}{4}(s-1) \log _{10} T+$ const.

Mass distribution indices, $s$, for each year are presented in Tables 5-7, in which are only included the cases with standard deviations not exceeding $10 \%$ of the index $s$. These tables are completed with Figs. 8-10, from which a relation between the activity curve of overdense echoes having $T \geq 0.4 \mathrm{~s}$ and the evaluated index $s$ is visible in each observed year.

To relate the meteor overdense duration, $T$, to the mass of a meteoroid we have used the formula for maximum electron line density, $\alpha_{\max }$, as a function of the meteoroid mass, $M_{\infty}$, its velocity, $V$, and radiant position embodied by the zenith distance, $z_{r}$, which had been published by Verniani (1973)

$\alpha_{\max }=2.73 \times 10^{10} M_{\infty}^{0.92} V^{3.91} \cos z_{r}$,

and have combined the line density with the expression connecting it to the radar echo duration (e.g. McKinley 1961)

$\alpha_{\max }=\frac{32}{27} \times 1.41 \times 10^{16} T \lambda^{-2} D$,

where $\lambda$ stands for the wavelength of radar and $D$ represents the ambipolar diffusion coefficient, we have arrived at the formula expressing the meteoroid mass as a function of echo duration and $\cos z_{r}$. Moreover, using $D=27.2 \mathrm{~m}^{2} \mathrm{~s}^{-1}, V=72 \mathrm{~km} \mathrm{~s}^{-1}$ and $\lambda=8 \mathrm{~m}$ this formula reads

$M_{\infty}=9.91 \times 10^{-6}\left(T / \cos z_{r}\right)^{1.087}$.

The corresponding masses as a function of time are listed in Table 8 for 3 duration limits. The radiant position is related to 2000 Nov. 18.

The lowest values of the mass distribution index $s$ was found in 2000 on Nov. 18 around 4h15m UT (i.e. within the earlier of the two peaks), when the activity was mainly caused by the prevalence of meteors with $T \geq 1.0 \mathrm{~s}$ in the data sample (see Table 5). Somewhat higher values of $s$ were determined in 2001 during both days (see Table 6), which were accompanied by the absence of underdense meteors. This is evidence for a slightly greater number of fainter meteors (but still considered as overdense) in this year display. The highest value of $s$ was discovered in 2002 (see Table 7). This observational fact gives evidence of further increase of the ratio of fainter meteors as compared to previous years.

\section{Comparison with predictions}

All comparisons are made regarding the error bars (i.e. \pm 15 min).

\subsection{0}

We compare our observation with Asher \& McNaught (2000). The maxima in Table 2 related to their prediction are printed in bold. Our comparison concerns only Nov. 18. A perfect agreement with both peaks on Nov. 18 is clearly visible in the first 
group $(T<0.4 \mathrm{~s})$. However, the same situation is not so for the remaining three groups. An inspection of our data of the last two groups (i.e. all echoes possessing $T \geq 1.0 \mathrm{~s}$ ) revealed that the more massive the particles, the earlier the occurrence of their main, rather widespread, maxima. The secondary maximum of meteors with duration $T \geq 0.4$ s on Nov. 18 (i.e. the earlier of the two peaks) appeared about 30 min later than it was predicted and the main maximum of this group (i.e. the later of the two peaks) was observed about 30 min earlier than it was expected.

\subsection{1}

No activity of underdense meteors was revealed in 2001. Thus, our discussion deal exclusively with overdense echoes (see Table 3). We have compared our observations with three author(s). These are: McNaught \& Asher (2001), Jenniskens (2001) and Lyytinen et al. (2001). Activity on Nov. 17 was not observable by us due to radiant position. For Nov. 18, our main maximum at $10 \mathrm{~h} 15 \mathrm{~m}$ UT coincides with both Jenniskens (2001) and Lyytinen et al. (2001) predictions very well regarding all three overdense groups. Their subsequent peak was not registered even though it could have been detected. Instead of this one we observed the peak preceding the major one at $6 \mathrm{~h} 45 \mathrm{~m}$ UT. It is evident from Fig. 6 that the activity of meteors with $T \geq 10.0$ s culminated one hour before the activity of the remaining echoes with lesser duration.

Remarkable activity was seen on Nov. 19 as we have already mentioned above in Sect. 3.2. This was not predicted by any author.

\subsection{2}

All the Leonid activity appeared only on Nov. 19. There were three maxima. The first maximum at $4 \mathrm{~h} 15 \mathrm{~m}$ UT is common to all four groups while the second one at $10 \mathrm{~h} 45 \mathrm{~m}$ UT was formed only by underdense echoes and those overdense with duration in interval $0.4 \mathrm{~s} \leq T<10.0 \mathrm{~s}$. This implies that the first maximum was due to activity of all echoes while the second one was due only to fainter echoes. Predictions of Jenniskens (2001), McNaught \& Asher (2002) and Vaubaillon (2002) were thus fulfilled. The maximum predicted by Jenniskens (2001), which was expected at $6 \mathrm{~h} 22 \mathrm{~m}$ UT confirmed the activity of only overdense echoes. The underdense echo activity peak occurred about 30 min later. Our results coincide also with the observations of Abe et al. (2003).

\section{Conclusions}

Three years of observations covered the solar longitude interval of shower activity from $234^{\circ} .85$ to $237^{\circ} .25$ (J2000.0). The shower activity in 2000 and 2001 spread over two days while in
2002 lasted only for several hours during one day. Even though the 2001 predicted activity should have spread over Nov. 17 and 18 our observation showed the actual activity manifested on Nov. 18 and 19. In general, the highest level of activity in all groups of durations was detected in 2002, the lowest one in 2001. No activity of underdense meteors was registered in 2001. The activity curves in 2000 and 2001 consisted of many peaks of widely fluctuating character while the curve in 2002 was formed by only one well pronounced maximum followed by a much smaller secondary one making this curve much smoother than the others. One of the smaller peaks in 2000 at $L_{\odot}=236^{\circ} .11$ (4h15m UT on Nov. 18) appeared also in 2001 at the same solar longitude (10h15m UT on Nov. 18) as the strongest maximum in this year. The peak in 2000 was mainly caused by presence of echoes of $T \geq 1.0 \mathrm{~s}$ whereas in 2001 all overdense echoes were responsible for the activity at this solar longitude. These two peaks are due to different trail encounters, i.e. it is just a coincidence that they appeared at the same solar longitude.

A degree of agreement between our radar observations and predictions was discussed in Sect. 5. Although we cannot confirm an outright coincidence of our results with predictions we can conclude that models of the filamentary structure of the Leonid meteor stream have been improving from year to year.

Unfortunately, we could not compare our values of $s$ with those predicted by Jenniskens (2001) due to different methods of determination.

Acknowledgements. This work was supported by the key project K3012103. The authors thank Dr. D. Asher for his very thorough refereeing which substantially improved this work.

\section{References}

Abe, S., Yano, H., Ebizuka, N., et al. 2003, Publ. Astron. Soc. Japan, 55,559

Asher, D. J., \& McNaught, R. H. 2000, WGN 28-5, 138

Belkovich, O. I., Ishmukhametova, M. G., \& Sulejmanov, N. I. 2001, Astron. vestnik, 35, 440

Jenniskens, P. 1994, A\&A, 287, 900

Jenniskens, P. 2001, in Meteoroids 2001, ed. B. Warmbein (SP-495, ESA, Kiruna, Sweden), 83

Kaiser, T. R. 1955, in Meteors, ed. T. R. Kaiser (London: Pergamon Press), 119

Lyytinen, E., Nissinen, M., \& van Flandern, T. 2001, WGN 29-4, 110

McKinley, D. W. R. 1961, Meteor Science and Engineering (New York: McGraw-Hill)

McNaught, R. H., \& Asher, D. J. 2001, WGN 29-5, 156

McNaught, R. H., \& Asher, D. J. 2002, WGN 30-5, 132

Plavcová, Z., \& Šimek, M. 1960, Bull. Astron. Inst. Czechosl., 25, 180

Šimek, M., \& Pecina, P. 2000, A\&A, 357, 777

Šimek, M., \& Pecina, P. 2001, A\&A, 365, 622

Vaubaillon, J. 2002, WGN 30-5, 144

Verniani, F. 1973, J. Geophys. Res., 78, 8429 
P. Pecina and D. Pecinová: Ondřejov radar observations of Leonids in 2000-2002, Online Material p 1

\section{Online Material}


P. Pecina and D. Pecinová: Ondřejov radar observations of Leonids in 2000-2002, Online Material p 2

Table 5. Mass distribution index, $s$, computed by means of formula (1), valid for 2000. Only indices whose standard deviations do not exceed $10 \%$ percentage of the index itself are shown. The index was computed within 30-min time intervals the midpoints of which are presented in the table. The first column contains the day in Nov, the second and third one contains hour, $\mathrm{h}$, and minute, $\mathrm{m}$, of the corresponding beginning time, in UT. Also solar longitude of the middle of corresponding span, $L_{\odot}$, is presented. The last but one column contains the values of $s$ while the last one contains standard deviation, s.d. of $s$.

\begin{tabular}{rrrccc}
\hline \hline & \multicolumn{5}{c}{2000} \\
\hline day & $\mathrm{h}$ & $\mathrm{m}$ & $L_{\odot}$ & $\mathrm{s}$ & $\mathrm{s.d}$. \\
\hline 17 & 1 & 15 & $234^{\circ} .98$ & 1.60 & 0.14 \\
17 & 1 & 45 & $235^{\circ} .00$ & 1.76 & 0.17 \\
17 & 2 & 45 & $235^{\circ} .04$ & 1.71 & 0.16 \\
17 & 3 & 45 & $235^{\circ} .08$ & 1.62 & 0.13 \\
17 & 6 & 15 & $235^{\circ} .19$ & 1.88 & 0.07 \\
17 & 6 & 45 & $235^{\circ} .21$ & 1.02 & 0.05 \\
17 & 7 & 45 & 235.25 & 2.19 & 0.13 \\
17 & 8 & 15 & $235^{\circ} .27$ & 2.36 & 0.15 \\
17 & 8 & 45 & $235^{\circ} .29$ & 2.54 & 0.17 \\
17 & 9 & 15 & $235^{\circ} .32$ & 3.65 & 0.29 \\
17 & 11 & 45 & $235^{\circ} .42$ & 2.18 & 0.19 \\
17 & 13 & 45 & $235^{\circ} .88$ & 1.61 & 0.10 \\
18 & 0 & 45 & $235^{\circ} .97$ & 1.48 & 0.14 \\
18 & 1 & 15 & $235^{\circ} .99$ & 1.51 & 0.09 \\
18 & 1 & 45 & 236.01 & 1.40 & 0.03 \\
18 & 2 & 15 & 236.03 & 1.21 & 0.05 \\
18 & 2 & 45 & 236.05 & 1.16 & 0.05 \\
18 & 3 & 15 & 236.07 & 1.14 & 0.02 \\
18 & 3 & 45 & 236.09 & 1.13 & 0.03 \\
18 & 4 & 15 & 236.11 & 1.20 & 0.06 \\
18 & 4 & 45 & 236.13 & 1.16 & 0.03 \\
18 & 5 & 15 & 236.16 & 1.21 & 0.05 \\
18 & 5 & 45 & 236.18 & 1.22 & 0.05 \\
18 & 6 & 15 & 236.20 & 1.27 & 0.02 \\
18 & 6 & 45 & 236.22 & 1.28 & 0.01 \\
18 & 7 & 15 & 236.24 & 1.51 & 0.02 \\
18 & 7 & 45 & 236.26 & 1.57 & 0.03 \\
18 & 8 & 15 & 236.28 & 1.54 & 0.03 \\
18 & 8 & 45 & 236.30 & 2.12 & 0.14 \\
18 & 9 & 15 & 236.32 & 1.34 & 0.12 \\
18 & 9 & 45 & 236.34 & 1.39 & 0.11 \\
18 & 10 & 15 & 236.37 & 1.77 & 0.18 \\
\hline & & & & & \\
& &
\end{tabular}

Table 6. The same as in Table 5 but for 2001.

\begin{tabular}{|c|c|c|c|c|c|}
\hline \multicolumn{6}{|c|}{2001} \\
\hline day & $\mathrm{h}$ & $\mathrm{m}$ & $L_{\odot}$ & $\mathrm{s}$ & s.d. \\
\hline 17 & 22 & 15 & $235^{\circ} 61$ & 2.64 & 0.14 \\
\hline 18 & 23 & 15 & $235^{\circ} .65$ & 2.82 & 0.28 \\
\hline 18 & 1 & 45 & $235^{\circ} .76$ & 1.39 & 0.08 \\
\hline 18 & 2 & 15 & $235^{\circ} .78$ & 1.40 & 0.07 \\
\hline 18 & 2 & 45 & $235^{\circ} .80$ & 1.23 & 0.06 \\
\hline 18 & 3 & 45 & $235^{\circ} .84$ & 1.03 & 0.03 \\
\hline 18 & 4 & 15 & $235^{\circ} .86$ & 1.10 & 0.03 \\
\hline 18 & 4 & 45 & $235^{\circ} .88$ & 1.15 & 0.06 \\
\hline 18 & 5 & 15 & $235^{\circ} .90$ & 1.05 & 0.01 \\
\hline 18 & 5 & 45 & $235^{\circ} .92$ & 1.11 & 0.02 \\
\hline 18 & 6 & 45 & $235^{\circ} .97$ & 1.12 & 0.04 \\
\hline 18 & 7 & 15 & $235^{\circ} .99$ & 1.23 & 0.05 \\
\hline 18 & 7 & 45 & $236^{\circ} 01$ & 1.16 & 0.04 \\
\hline 18 & 8 & 15 & $236^{\circ} .03$ & 1.28 & 0.06 \\
\hline 18 & 8 & 45 & $236^{\circ} 05$ & 1.54 & 0.07 \\
\hline 18 & 9 & 15 & $236^{\circ} .07$ & 1.52 & 0.06 \\
\hline 18 & 9 & 45 & $236^{\circ} .09$ & 1.54 & 0.07 \\
\hline 18 & 10 & 15 & $236^{\circ} .11$ & 1.28 & 0.04 \\
\hline 18 & 10 & 45 & $236^{\circ} .13$ & 1.29 & 0.03 \\
\hline 18 & 11 & 15 & $236^{\circ} .15$ & 1.19 & 0.06 \\
\hline 18 & 12 & 15 & $236^{\circ} .20$ & 2.48 & 0.25 \\
\hline 18 & 13 & 15 & $236^{\circ} .62$ & 2.24 & 0.09 \\
\hline 18 & 13 & 45 & $236^{\circ} 64$ & 1.73 & 0.06 \\
\hline 19 & 23 & 15 & $236^{\circ} .66$ & 2.25 & 0.11 \\
\hline 19 & 23 & 45 & $236^{\circ} 68$ & 1.71 & 0.09 \\
\hline 19 & 0 & 15 & $236^{\circ} .70$ & 1.72 & 0.10 \\
\hline 19 & 0 & 45 & $236^{\circ} .72$ & 1.11 & 0.05 \\
\hline 19 & 1 & 15 & $236^{\circ} .74$ & 1.47 & 0.04 \\
\hline 19 & 1 & 45 & $236^{\circ} .76$ & 1.26 & 0.07 \\
\hline 19 & 2 & 15 & $236^{\circ} .79$ & 1.37 & 0.03 \\
\hline 19 & 2 & 45 & $236^{\circ} .81$ & 1.09 & 0.03 \\
\hline 19 & 3 & 15 & $236^{\circ} 83$ & 1.21 & 0.04 \\
\hline 19 & 3 & 45 & $236^{\circ} 85$ & 1.24 & 0.04 \\
\hline 19 & 4 & 15 & $236^{\circ} .87$ & 1.17 & 0.03 \\
\hline 19 & 4 & 45 & $236^{\circ} 89$ & 1.82 & 0.06 \\
\hline 19 & 5 & 15 & $236^{\circ} .91$ & 1.10 & 0.02 \\
\hline 19 & 5 & 45 & $236^{\circ} .93$ & 1.32 & 0.10 \\
\hline 19 & 6 & 15 & $236^{\circ} .95$ & 1.40 & 0.05 \\
\hline 19 & 6 & 45 & $236^{\circ} .97$ & 1.28 & 0.07 \\
\hline 19 & 8 & 45 & $237^{\circ} .06$ & 1.38 & 0.07 \\
\hline
\end{tabular}


P. Pecina and D. Pecinová: Ondřejov radar observations of Leonids in 2000-2002, Online Material p 3

Table 7. The same as in Table 5 but for 2002 .

\begin{tabular}{rrrccc}
\hline \hline & \multicolumn{5}{c}{2002} \\
\hline day & \multicolumn{1}{c}{$\mathrm{h}$} & $\mathrm{m}$ & $L_{\odot}$ & $\mathrm{s}$ & $\mathrm{s.d}$ \\
\hline 18 & 23 & 45 & 236.42 & 1.89 & 0.12 \\
19 & 0 & 15 & 236.44 & 1.21 & 0.09 \\
19 & 0 & 45 & 236.46 & 1.24 & 0.03 \\
19 & 1 & 15 & 236.48 & 1.18 & 0.03 \\
19 & 1 & 45 & 236.50 & 1.56 & 0.04 \\
19 & 2 & 15 & 236.53 & 1.40 & 0.03 \\
19 & 2 & 45 & 236.55 & 1.11 & 0.03 \\
19 & 3 & 15 & 236.57 & 1.17 & 0.02 \\
19 & 3 & 45 & 236.59 & 1.34 & 0.04 \\
19 & 4 & 15 & 236.61 & 1.35 & 0.03 \\
19 & 4 & 45 & 236.63 & 1.31 & 0.03 \\
19 & 5 & 15 & 236.65 & 1.38 & 0.03 \\
19 & 5 & 45 & 236.67 & 1.22 & 0.02 \\
19 & 6 & 15 & 236.69 & 1.29 & 0.02 \\
19 & 6 & 45 & 236.71 & 1.41 & 0.04 \\
19 & 7 & 15 & 236.74 & 1.30 & 0.03 \\
19 & 7 & 45 & 236.76 & 2.13 & 0.16 \\
19 & 8 & 15 & 236.78 & 1.69 & 0.06 \\
19 & 8 & 45 & 236.80 & 1.20 & 0.05 \\
19 & 9 & 15 & 236.82 & 1.34 & 0.05 \\
19 & 9 & 45 & 236.84 & 1.13 & 0.05 \\
19 & 10 & 45 & 236.88 & 2.33 & 0.09 \\
19 & 11 & 15 & 236.90 & 2.19 & 0.18 \\
19 & 11 & 45 & 236.92 & 2.05 & 0.16 \\
19 & 12 & 15 & 236.95 & 2.52 & 0.21 \\
19 & 12 & 45 & 236.97 & 2.35 & 0.12 \\
\hline
\end{tabular}

